\title{
TU/e emonowne

\section{Heat transfer and flame stabilization of laminar premixed flames anchored to a heat-flux burner}

\section{Citation for published version (APA):}

Yu, J. F., Yu, R., Bai, X. S., Bastiaans, R. J. M., Van Oijen, J. A., \& De Goey, L. P. H. (2016). Heat transfer and flame stabilization of laminar premixed flames anchored to a heat-flux burner. International Journal of Hydrogen Energy, 41(3), 2037-2051. https://doi.org/10.1016/j.ijhydene.2015.11.105

\section{Document license: \\ TAVERNE}

DOI:

10.1016/j.ijhydene.2015.11.105

\section{Document status and date:}

Published: 21/01/2016

\section{Document Version:}

Publisher's PDF, also known as Version of Record (includes final page, issue and volume numbers)

\section{Please check the document version of this publication:}

- A submitted manuscript is the version of the article upon submission and before peer-review. There can be important differences between the submitted version and the official published version of record. People interested in the research are advised to contact the author for the final version of the publication, or visit the $\mathrm{DOI}$ to the publisher's website.

- The final author version and the galley proof are versions of the publication after peer review.

- The final published version features the final layout of the paper including the volume, issue and page numbers.

Link to publication

\section{General rights}

Copyright and moral rights for the publications made accessible in the public portal are retained by the authors and/or other copyright owners and it is a condition of accessing publications that users recognise and abide by the legal requirements associated with these rights.

- Users may download and print one copy of any publication from the public portal for the purpose of private study or research.

- You may not further distribute the material or use it for any profit-making activity or commercial gain

- You may freely distribute the URL identifying the publication in the public portal.

If the publication is distributed under the terms of Article 25fa of the Dutch Copyright Act, indicated by the "Taverne" license above, please follow below link for the End User Agreement:

www.tue.nl/taverne

Take down policy

If you believe that this document breaches copyright please contact us at:

openaccess@tue.nl

providing details and we will investigate your claim. 


\title{
Heat transfer and flame stabilization of laminar premixed flames anchored to a heat-flux burner
}

\author{
J.F. Yu ${ }^{a, b}$, R. Yu ${ }^{a}$, X.S. Bai ${ }^{a, *}$, R.J.M. Bastiaans ${ }^{c}$, J.A. van Oijen ${ }^{c}$, \\ L.P.H. de Goey ${ }^{c}$ \\ a Division of Fluid Mechanics, Lund University, SE 22100 Lund, Sweden \\ ${ }^{\mathrm{b}}$ College of Aerospace Science and Engineering, National University of Defense Technology, 410073 Changsha, China \\ ${ }^{\mathrm{c}}$ Department of Mechanical Engineering, Eindhoven University of Technology, Eindhoven, The Netherlands
}

\section{A R T I C L E I N F O}

Article history:

Received 18 August 2015

Received in revised form

17 November 2015

Accepted 18 November 2015

Available online 21 December 2015

Keywords:

Laminar premixed flame

Heat-flux burner

Cellular flames

Intrinsic instability

Burner non-uniformity

Numerical simulation

\begin{abstract}
A B S T R A C T
Measurement of the burning velocity of unstretched laminar hydrogen/air premixed flames suffers from large uncertainties owing to the highly diffusive nature of hydrogen that can give rise to flame instability. This paper reports on a numerical study of the structures and stability of laminar premixed $\mathrm{CH}_{4} / \mathrm{O}_{2} / \mathrm{CO}_{2}$ flames and $\mathrm{H}_{2} / \mathrm{O}_{2} / \mathrm{N}_{2}$ flames anchored to a heat-flux burner using a high-order numerical method with detailed chemical kinetic mechanisms and detailed transport properties. The aim is to elucidate the effect of the flow and temperature inhomogeneity generated by the burner plate holes on flame structures and burning velocity. Heat transfer flux between the burner plate and the surrounding gaseous mixture is investigated under various standoff distances and burner plate temperatures. The burning velocity and the detailed flow, temperature and species distributions in flames with a zero net heat flux between the flames and the burner plate are analyzed. It is found that for the methane flames, when the standoff distance is sufficiently small, the burner can essentially suppress the intrinsic flame instability, but the plate holes can give rise to flame wrinkles of the size of the holes. At high standoff distances, the non-uniformity of the flow from the burner plate holes has a minor effect on the flame surface wrinkling; however, large-scale cellular structures can appear on the flame surface due to intrinsic flame instability. For the studied methane flames the effect of non-uniformity of the flow from the burner plate holes on the burning velocity is fairly small. For the studied hydrogen flames the burner plate could not totally suppress the intrinsic flame instability. The intrinsic flame instability can give rise to a significant increase in the flame surface area and mean burning velocity, with more than $25 \%$ increase in the burning velocity.
\end{abstract}

Copyright @ 2015, Hydrogen Energy Publications, LLC. Published by Elsevier Ltd. All rights reserved.

\footnotetext{
* Corresponding author.

E-mail address: xue-song.bai@energy.lth.se (X.S. Bai).
} 


\section{Introduction}

A key parameter of unstretched premixed flames for various combustible mixtures is the laminar burning velocity, for which several kinds of burner systems have been developed to do experimental measurements. In general, laminar premixed flames associated with a burner are affected by the burner geometry. In certain situations, such as those of strained flat flames stabilized in counterflow burners or developing spherical flames in constant-volume enclosures, the flames are stretched. In some burner configurations and fuel/oxidizer compositions small-scale cellular shaped structures may appear on the flame surface. One may employ extrapolation methods to determine the unstretched burning velocity on the basis of that of the stretched one [1,2]. However, it is generally difficult to use extrapolation methods to correct the burning velocity of flames with small-scale wrinkling due to the cellular instability that exists.

It is highly desirable to have a flat-flame burner in order to be able to generate unstretched planar flames. Powling [3] was the first to report the use of a flat-flame burner. The principle of the method is the following: the flame is anchored to the burner by balancing the inflow velocity to the burning velocity. The latter can vary with the standoff distance between the flame and the burner. A smaller distance leads to a lower burning velocity due to the heat loss from the flame to the burner. Botha and Spalding [4] proposed a method for stabilizing the flame at a specific standoff distance by controlling the inflow velocity of the reactant mixture and the cooling rate of the burner plate. The flame is essentially non-adiabatic since there is heat loss from the flame to the burner. Due to heat loss the flame thickness increases and the ratio of density or temperature across the flame decreases. This was shown to suppress the cellular instability [5].

Theoretical analyses [6-10] and numerical simulations [11-20] of freely propagating laminar premixed flames (far from the burner) show that the hydrodynamic and diffusional-thermal mechanisms can trigger the onset of cellular flames. Thin flames with high density ratios between gases on the unburned and burned side of the flame are unconditionally unstable due to the deviation of flow streamlines across oblique flames (hydrodynamic effect [6,7]). In addition to this, fuel-lean flames with Lewis number well below unity (e.g. lean hydrogen/air flames) tend to redistribute heat and fuel/air ratio at the flame front such that the flames become increasingly cellular (diffusional-thermal effect $[9,10])$, whereas flames with Lewis number larger than unity tend to be pulsating [21] owing to the diffusional-thermal effect.

Previous theoretical works focused on the diffusionalthermal effects (i.e. assuming constant density in the flow field) on flame instability in porous plug burner flames with heat loss to the burners. For small wave number disturbances, Buckmaster [21] developed a dispersion relation based on a large activation energy asymptotic analysis and one-step chemistry, which reveals that the porous plug burner tends to suppress the cellular flame instability in mixtures with Lewis number less than unity whereas for mixtures with Lewis number larger than unity the burner can enhance the onset of pulsating instability when the flame is not very close to the burner plate. There is a minimum standoff distance from the flame to the burner plate within which both the cellular and pulsating instabilities can be suppressed. The recent works of Kurdyumov et al. [22,23] reveal the diffusional-thermal effect on the onset of pulsating flames near the porous plug burner; it was found that with thicker burner plate and higher density ratio the flames are easier to develop into a pulsating mode, and radiative heat loss from the flame can further promote the onset of pulsating flames and cellular flames. In previous theoretical studies heat loss from the flame to the burner plays an essential role in the flame instability. For example, the analysis of Joulin [24] indicated that the pulsating instability was a result of the time lag of the travelling temperature disturbances between the burner surface and the flame front.

In order to enable an adiabatic flame to be anchored to the burner, De Goey and his co-workers [25-27] improved a cooled flat-flame burner to a so-called heat-flux burner. The burner plate has a temperature higher than the unburned fuel/ oxidizer mixture; when passing through the plate the gas mixture receives heat from the plate. By adjusting the velocity of the unburned fuel/oxidizer mixture the flame can be stabilized in the proximity of the burner, i.e. at a characteristic standoff distance from the flame to the burner surface. When the standoff distance is large the net heat transfer flux from the plate to the gas is positive, whereas if the standoff distance is small heat can be transferred from the flame to the plate, hence the net heat flux on the burner plate is a function of the standoff distance, burner plate temperature and temperature of the unburned fuel/oxidizer mixture. When the latter temperatures are prescribed, the standoff distance becomes the control parameter for the net heat flux between the burner plate and surrounding gas. In practice, the standoff distance is controlled by prescribing the mixture inflow velocity, where the net heat flux theoretically becomes zero if the gas velocity is equal to the adiabatic burning velocity.

With the heat-flux burner, previous experimental and numerical studies have shown that the flames may develop to cellular shape when the standoff distance is large [28-30]. It is unclear how the burner porosity and hole size, which could disturb the flow field in the proximity of the burner plate, would affect the onset of flame instability. Consequently, when the flame is moderately cellular, an important question is the impact of the cellular flame front on the net heat flux between the porous plate and the surrounding gas, and the implications of this on the determination of the adiabatic unstretched laminar flame speed. This has motivated the present study in which we employ a recently developed high accuracy numerical method [31] to simulate the detailed reaction zone structures and the heat transfer process, aiming at clarifying the various instability mechanisms and the burner plate effect.

\section{Governing equations and numerical methods}

Heat transfer and flame stabilization of premixed $\mathrm{CH}_{4} / \mathrm{O}_{2} / \mathrm{CO}_{2}$ and $\mathrm{H}_{2} / \mathrm{O}_{2} / \mathrm{N}_{2}$ mixtures passing through the porous plate of a flat-flame heat-flux burner are studied using high fidelity 
numerical simulations employing detailed transport and an elementary chemical reaction mechanism. Under the presently investigated flame conditions the flow speed is low and essentially it can be assumed as a low Mach number flow. The physical pressure can be decomposed into two parts, a thermodynamic pressure that is uniform throughout the domain and a hydrodynamic pressure that appears in the momentum equations. The mixture considered is in the gas phase, without body force and with negligible thermal radiation. The governing equations for such a system are made up of the transport equations for the species mass fractions and energy, the Navier-Stokes equations, the continuity equation, and the equation of state for ideal gas,

$\rho \frac{D Y_{k}}{D t}=-\frac{\partial \rho Y_{k} V_{k, i}}{\partial x_{i}}+\dot{\omega}_{k}$

$\rho C_{p} \frac{D T}{D t}=-\sum_{k=1}^{N} h_{k} \dot{\omega}_{k}-\left(\rho \sum_{k=1}^{N} C_{p, k} Y_{k} V_{k, i}\right) \frac{\partial T}{\partial x_{i}}+\frac{\partial}{\partial x_{i}}\left(\lambda \frac{\partial T}{\partial x_{i}}\right)$

$\rho \frac{D u_{i}}{D t}=-\frac{\partial p}{\partial x_{i}}+\frac{\partial \tau_{i j}}{\partial x_{j}}$

$\frac{\partial u_{i}}{\partial x_{i}}=-\frac{1}{\rho} \frac{D \rho}{D t}$

$P=\rho R T \sum_{k=1}^{N} \frac{Y_{k}}{W_{k}}$

where $\rho$ is density; $Y_{k}$ is mass fraction of species $k$; $u_{i}$ is the velocity component in the $x_{i}$-direction; $V_{k, i}$ is the diffusion velocity of species $k$ in the $x_{i}$-direction; $\dot{\omega}_{k}$ is the reaction rate of species $k ; p$ is the hydrodynamic pressure; $P$ is the thermodynamics pressure, which is 1 atm in the present study; $\tau_{i j}$ is the component of viscous stress tensor; $h_{k}$ is the specific enthalpy of species $k ; C_{p, k}$ is the specific heat capacity of species $k$ at constant pressure; $T$ is the temperature; $\lambda$ is the thermal diffusivity; $W_{k}$ is the molecular weight of species $k ; D /$ $D t$ denotes the material derivative of a quantity. The diffusion velocity is modeled using Fick's law with mixture-averaged diffusion coefficients [32].

The continuity equation has been deliberately written in terms of the material derivative of density, which then makes use of the equation of state (5) to couple the continuity equation (4) with the species transport equation (1) and the energy transport equation (2). In this way, robust numerical stability can be achieved when high density gradients exist in the flow field [31].

The temporal integration of the governing equations is performed using a second order operator splitting scheme with a stiff solver for chemical reaction rates. In this method all variables are computed explicitly except the hydrodynamic pressure, which is obtained from the numerical solution of a variable coefficient Poisson equation derived from the momentum equations and the continuity equation. The pressure equation is solved with a multi-grid method [33]. The spatial derivatives in the governing equations are discretized using a $6^{\text {th }}$-order central difference scheme except the convection terms in the species transport and energy transport equations, which are discretized using a $5^{\text {th }}$-order WENO scheme
[34] to avoid wiggles in the mass fractions of species and temperature that can lead to unphysical solution. The solver is parallelized based on the domain decomposition method. The code is written in a vector form enabling simulations from 1D to 3D. More details of the solver and numerical methods can be found in Ref. [31].

\section{Computational cases, initial and boundary conditions}

The computational cases are chosen following the work of de Goey et al. [29], where two-dimensional methane/air flames around one of holes of the heat-flux burner was studied numerically. Since only one hole was modeled, the large-scale flame instability observed in the heat-flux burner [30] was not captured. We consider here a two-dimensional domain with multiple holes in the calculation.

Fig. 1 illustrates schematically the burner, the computational domain and boundary conditions considered in this study. The burner hole has a width of $l_{1}$ and wall width of $l_{2}$. The thickness of the wall is $h$. Four flames, $\mathrm{CH}_{4} / \mathrm{O}_{2} / \mathrm{CO}_{2}$ flames (F1a and F1b) and $\mathrm{H}_{2} / \mathrm{O}_{2} / \mathrm{N}_{2}$ flames (F2a and $\mathrm{F} 2 \mathrm{~b}$ ), are considered. The burner plate porosity defined as $l_{1} /\left(l_{1}+l_{2}\right)$ is set to 0.469 , with $l_{1}=0.938 \delta_{\mathrm{L}}$ and $l_{2}=1.062 \delta_{\mathrm{L}}$ for the four flame cases, where $\delta_{\mathrm{L}}$, defined as the ratio of the maximal temperature difference between the burned and unburned gases to the maximal temperature gradient, is the characteristic thickness of the adiabatic planar unstretched laminar flame under corresponding unburned mixture conditions. The burner plate thickness for the four flames is set as $h=4.23 \delta_{\mathrm{L}}$. Since the thickness-to-width ratio $\left(h / l_{2}\right)$ is rather large (about 4$)$ the burner wall temperature is assumed to be constant. This avoids the computation of heat transfer inside the wall. The burner plate temperature $T_{p}$ is varied to generate adiabatic flames with various standoff distances, $\mathrm{x}_{\mathrm{f}}$. A summary of the burner parameters is given in Table 1 . The burner porosity and hole size are relevant to those of the heat-flux burners in Eindhoven and Lund [30,35].

The computational domain has a width of $16 \delta_{\mathrm{L}}$. In the present study $\delta_{\mathrm{L}}$ is about $0.5 \mathrm{~mm}$, hence the domain width is about $8 \mathrm{~mm}$, which is about one fourth of the burner plate used in the experiments of Hermanns [35]. The length of the computational domain (along the streamwise direction) is not very influential on the cellular instability and the heat transfer

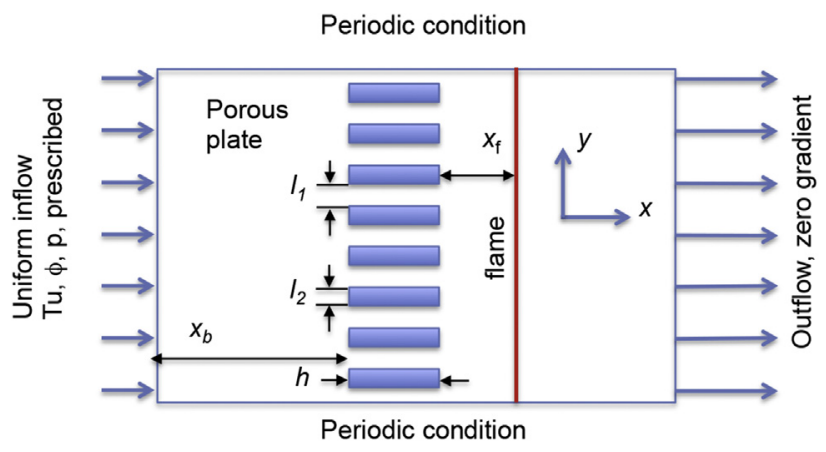

Fig. 1 - Computational domain, burner/mixture parameters and boundary conditions. 
Table 1 - Burner plate parameters and setup of the computational domain.

Burner plate parameters

Width of the holes $l_{1} / \delta_{\mathrm{L}}$

Width of the plate wall $l_{2} / \delta_{\mathrm{L}}$

Thickness of the plate wall $\mathrm{h} / \delta_{\mathrm{L}}$

Plate temperature $\mathrm{Tp}[\mathrm{K}]$

Computational domain

Width of the domain, $\mathrm{H} / \delta_{\mathrm{L}}$

Length of the domain, $\mathrm{L} / \delta_{\mathrm{L}}$

Burner position in the domain, $\mathrm{x}_{\mathrm{b}} / \delta_{\mathrm{L}}$

studies in the present case. Thus, we have chosen a domain length of $16 \delta_{\mathrm{L}}$. The number of computational cells (with a uniform grid spacing) in both the transverse direction and the streamwise direction is 256 . About 16 cells are used to resolve the reaction zone, which was shown to be adequate. The distance between the burner plate and the inlet of the computational domain is set to about $\mathrm{x}_{\mathrm{b}}=3.77 \delta_{\mathrm{L}}$, which allows for the use of uniform unburned mixture inflow conditions at the inlet.

The flame conditions and computational domain are summarized in Tables 1 and 2. For all flame cases, the thermodynamic pressure is $1 \mathrm{~atm}$ and temperature of the unburned mixture $\left(\mathrm{T}_{\mathrm{u}}\right)$ is $298 \mathrm{~K}$. The oxidizer of the methane flames (flames $\mathrm{F} 1 \mathrm{a}$ and $\mathrm{F} 1 \mathrm{~b}$ ) is a mixture of $\mathrm{O}_{2}$ and $\mathrm{CO}_{2}$ with a molar fraction of $\mathrm{O}_{2}$ in the oxidizer of 0.35 (parameter $\mathrm{D}$ in Table 2). This flame has been studied experimentally in Ref. [30]. The oxidizer in the hydrogen flames (flames F2a and F2b) is a mixture of $\mathrm{O}_{2}$ and $\mathrm{N}_{2}$ with a molar fraction of $\mathrm{O}_{2}$ in the oxidizer of 0.18 . These cases are chosen to explore both the hydrodynamic effect (the methane flames with higher density ratio) and the diffusional-thermal effect (the hydrogen flames with lower Lewis numbers and lower density ratio) on the stability of the heat-flux burner flames.

In the following discussion all lengths are normalized with the flame thickness $\delta_{\mathrm{L}}$, and time is normalized with the flame time $\delta_{\mathrm{L}} / \mathrm{S}_{\mathrm{L}}$, e.g., the domain width is thus $\mathrm{H}=16$, and the distance between the domain inlet and the burner plate is $\mathrm{x}_{\mathrm{b}}=3.77$. The non-dimensional time is denoted as $\mathrm{t}^{*}$ to distinguish it from the physical time t. Other physical quantities, e.g., velocity, temperature, heat fluxes, etc., are however not normalized.

For the two mixtures numerical simulations are first carried out for the corresponding one-dimensional planar freely propagating adiabatic flame configuration. The simulations are done using the same numerical method described above. For the methane flames Smooke's mechanism [36] is used and for the hydrogen flame the $\mathrm{H}_{2}$ subset of the Peters' mechanism [37] is used, which contains 9 species and 38 reactions. Detailed transport properties and a uniform grid spacing of
$5 \mu \mathrm{m}$ are used in the simulations. From these simulations the key flame parameters are obtained. As given in Table 2, the density ratios between the unburned and burned gases are 6.89 and 4.9 for the methane flames and the hydrogen flames, respectively. The thicknesses of the two flames are similar, about $0.5 \mathrm{~mm}$. The laminar burning velocity of the methane flames (F1a and F1b) is $0.236 \mathrm{~m} / \mathrm{s}$ and for the hydrogen flames (F2a and F2b) it is $0.39 \mathrm{~m} / \mathrm{s}$.

The initial flame is placed at a standoff distance of $\bar{x}_{f}$, i.e.

$x=f\left(y, t^{*}=0\right)=x_{b}+h+\bar{x}_{f}+\varepsilon \sin (2 \pi y / H)$,

where a slightly wrinkled flame front is assumed to have a sinusoidal wave shape with a wavelength of the domain width (H) and an amplitude of $\varepsilon=0.1$. The one-dimensional unstretched flame profile discussed above is used as the initial field. To incorporate the profile the flame front is defined at the position of the maximal heat release rate. The inlet flow is assumed to be the unburned mixture with a uniform velocity of $\mathrm{U}=\mathrm{S}_{\mathrm{L}}$ initially, and then tuned to get a time-independent mean flame position with a total net heat flux of zero value (for the F1a and F1b flames) or a specified mean standoff distance (for the F2a and F2b flames). At the outlet the dependent variables are assumed to have a zero gradient. Periodic boundary conditions are applied on the transverse boundaries to allow for the development of cellular instabilities in the transverse direction.

\section{Results and discussions}

To find the adiabatic condition, a net heat flux between the burner plate walls and the surrounding gas is calculated under various standoff distances and burner plate temperatures. By definition the net heat flux from the gas to the plate walls is,

$d Q=\int_{\text {wall surface }} d q d s, d q=\lambda(\nabla T \cdot \vec{n})$

where $\vec{n}$ is the unit vector perpendicular to wall surface pointing outwards, and $\mathrm{dq}$ is the local heat flux on the wall surface. Only conductive heat transfer is considered in the calculation; radiative heat transfer is neglected.

To analyze the evolution of the flame front, Fourier decomposition of the flame front function is carried out,

$x=f\left(y, t^{*}\right)=A_{0}\left(t^{*}\right)+\sum_{n=1}^{N} A_{n}\left(t^{*}\right) \sin \left(k_{n} y\right)$

The flame front function is a superposition of sine waves with various wavenumbers and amplitudes. Wavenumber $k_{n}$ is defined as $k_{n}=2 \pi n / H$. Its associated amplitude is $A_{n}$, where $n$ is the number of waves along the flame front (in the lateral $y$

Table 2 - Numerical setup of the flame cases and key parameters.

\begin{tabular}{llcccccccc} 
Flames & Mixture & $\mathrm{D}$ & $\varphi$ & $\mathrm{T}_{\mathrm{p}}[\mathrm{K}]$ & $\mathrm{Q}_{\mathrm{L}}[\mathrm{kW} / \mathrm{m}]$ & $\rho_{\mathrm{u}} / \rho_{\mathrm{b}}$ & $\delta_{\mathrm{L}}[\mu \mathrm{m}]$ & $\mathrm{S}_{\mathrm{L}}[\mathrm{cm} / \mathrm{s}]$ & $\mathrm{Le} \mathrm{eff}$ \\
\hline $\mathrm{F} 1 \mathrm{a}$ & $\mathrm{CH}_{4} / \mathrm{O}_{2} / \mathrm{CO}_{2}$ & 0.35 & 0.7 & 368 & 7.30 & 6.89 & 473 & 23.6 \\
$\mathrm{~F} 1 \mathrm{~b}$ & $\mathrm{CH}_{4} / \mathrm{O}_{2} / \mathrm{CO}_{2}$ & 0.35 & 0.7 & 303 & 7.30 & 6.89 & 473 & 0.78 \\
$\mathrm{~F} 2 \mathrm{a}$ & $\mathrm{H}_{2} / \mathrm{O}_{2} / \mathrm{N}_{2}$ & 0.18 & 0.56 & 368 & 5.96 & 4.90 & 487 & 23.6 \\
F2b & $\mathrm{H}_{2} / \mathrm{O}_{2} / \mathrm{N}_{2}$ & 0.18 & 0.56 & 303 & 5.96 & 4.90 & 487 & 39.0 & 0.78 \\
\hline
\end{tabular}


direction). With $\mathrm{n}=1$ and $\mathrm{H}=16$, the wavenumber is $k_{1}=2 \pi \cdot 1 / H=0.39$.

To investigate the effects of burner induced flow nonuniformity on the flames, the following three quantities were examined,

$$
\begin{gathered}
F_{S}=\frac{1}{H} \int_{0}^{H} \sqrt{1+\left(d x_{f}(y) / d y\right)^{2}} d y, \\
H R R=Q / Q_{L}, Q=\iint_{\Omega} \omega_{T} d x d y, \quad \omega_{T}=\sum_{k} h_{k} \dot{\omega}_{k}, \\
S_{D}=S_{d} / S_{L}, S_{d}=\frac{1}{H} \int_{0}^{H} S_{d, u}(y) \sqrt{1+\left(d x_{f}(y) / d y\right)^{2}} d y
\end{gathered}
$$

where $F_{\mathrm{s}}$ is the surface length of the flame front normalized by the initial flame surface length $(\mathrm{H})$; $\mathrm{Q}$ is the total heat release rate in the domain $\Omega$ as a whole; HRR is $Q$ normalized by its value at the initial planar flame, $Q_{\mathrm{L}} . \mathrm{S}_{\mathrm{d}}$ is the mean laminar burning velocity of the flame front averaged along its transverse direction; $S_{D}$ is $S_{d}$ normalized by its initial value, $S_{L}$. $S_{d, u}$ is the local displacement velocity defined as

$S_{d, u}=\left.\frac{1}{\rho_{u}}\left(\rho \frac{D Y_{F}}{D t} /\left|\nabla Y_{F}\right|\right)\right|_{Y_{F}=Y_{F f}}$.

Here, $Y_{F}$ is the mass fraction of the fuel, and $Y_{F, f}$ is a reference mass fraction of the fuel, defined at the maximal temperature gradient in the $1 \mathrm{D}$ flame solution, which is about $36 \%$ of the mass fraction of methane in the unburned mixture for the methane flames, and $33 \%$ of the mass fraction of hydrogen in the unburned mixture for the hydrogen flames. The values of $\mathrm{Q}_{\mathrm{L}}$ and $\mathrm{S}_{\mathrm{L}}$ are given in Table 2 for the four flame cases.

\section{Evolution of flame instability (flames F1a and F1b)}

The simulations of flames $\mathrm{F} 1 \mathrm{a}$ and $\mathrm{F} 1 \mathrm{~b}$ start from an initial mean standoff distance of $\bar{x}_{f}=1$ for the $T_{p}=368 \mathrm{~K}$ case and $\bar{x}_{f}=2$ for $T_{p}=303 \mathrm{~K}$ case. The inlet flow velocity $U$ is firstly set as $U=S_{L}$ and according to the net heat flux (dQ calculated from Eq. (7)) it is adjusted such that the flame is stabilized at a standoff distance where $d Q=0$. When $d Q>0$ the flame is too close to the burner, so a higher inlet velocity has to be assigned. In the simulations the inflow velocity is updated every 10 time steps; for example, if dQ $>0.05 \mathrm{~W} / \mathrm{m}$ the inlet velocity is increased by $1 \mathrm{~mm} / \mathrm{s}$, while if $\mathrm{dQ}<0.05 \mathrm{~W} / \mathrm{m}$ the inlet velocity is increased by a smaller fraction of U, i.e. $0.02 \%$ of $\mathrm{U}$. If $\mathrm{dQ}<0$ a lower inlet velocity is assigned accordingly. This procedure can be demonstrated in Fig. 2, where the temporal evolution of the net heat flux dQ is shown together with the mean standoff distance $\mathrm{x}_{\mathrm{f}}$ and inlet velocity $\mathrm{U}$ for flames F1a and F1b at burner plate temperatures $T_{p}=368 \mathrm{~K}$ (F1a) and $303 \mathrm{~K}$ (F1b), respectively. For example, Fig. 2b shows that when the inlet velocity is initially set to $U=S_{L}$ and the mean standoff distance set to $\bar{x}_{f}=2\left(a t t^{*}=0\right)$ the mean flame propagates toward the burner and dQ $<-10 \mathrm{~W} / \mathrm{m}$; $\mathrm{U}$ is then decreased by an increment of $1 \mathrm{~mm} / \mathrm{s}$ (or $0.02 \%$ of $U$ ) until $\mathrm{dQ}>0$. Thereafter, $\mathrm{U}$ is increased until $\mathrm{dQ}<0$. It appears that this process oscillates for a rather long time $\left(t^{*}>30\right)$ and eventually the flame is stabilized at the condition of $d Q=0$. When $\mathrm{dQ}=0, \mathrm{x}_{\mathrm{f}}$ for cases $\mathrm{T}_{\mathrm{p}}=303 \mathrm{~K}$ and $368 \mathrm{~K}$ are 2.06 and 1.07, respectively. That is, when $T_{p}$ is increased, $x_{f}$ is decreased under the adiabatic flame condition.

The evolution of the flame surface of the methane flames is shown in Fig. 3. For the $\mathrm{T}_{\mathrm{p}}=368 \mathrm{~K}$ case the flame is stabilized when $t^{*}>10$; for the $T_{p}=303 \mathrm{~K}$ case the flame is stabilized when $t^{*}>30$. For the two cases shown in this figure the initial disturbance has a wave number of $\mathrm{k}_{1}=0.39$, i.e. the wavelength is equal to the domain width. It is seen that when the flame is moving closer to the burner (decreasing $\mathrm{x}$ ) the high plate temperature case $\left(T_{p}=368 \mathrm{~K}\right)$ shows a steady flame front with $\mathrm{k}_{8}$ mode cells. The number of wrinkle cells is identical to the number of holes in the burner plate. As shown later the onset of these cells is due to the non-uniformity of the burner plate. The walls in the plate generate a non-uniform flow velocity as well as non-uniform distribution of the temperature and composition of the mixture along the burner surface, which in turn causes the flame to wrinkle according to the size of the holes. No other mode can be seen in the flame front in the high plate temperature case (F1a). For the low plate temperature case (F1b) a large-scale two-cell structure can be seen, Fig. 3b. The two-cell mode, i.e. the $\mathrm{k}_{2}$ mode, is due to intrinsic flame instability. The effect of the burner plate holes is more evident in the earlier stage of the evolution process. At a later stage the burner effect on the flame front is fairly small, although one may notice the $\mathrm{k}_{8}$ mode in the middle of the domain $\left(y / \delta_{\mathrm{L}}=8\right)$. This can be understood from Fig. $3 \mathrm{~b}$. In the low plate temperature case (F1b) the standoff distance is large and hence the non-uniformity of the flow in front of the flame is less pronounced.

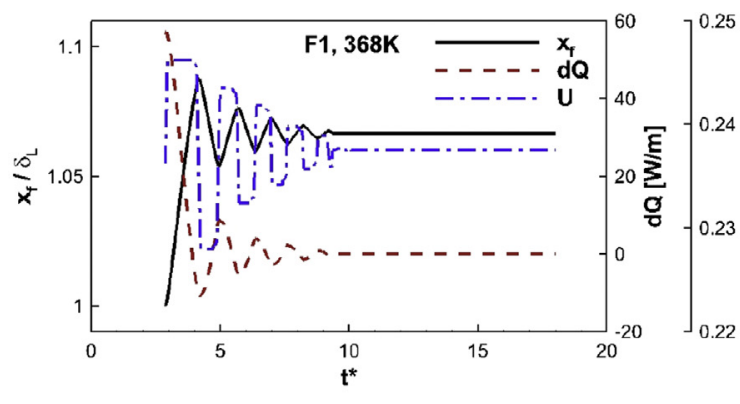

(a)

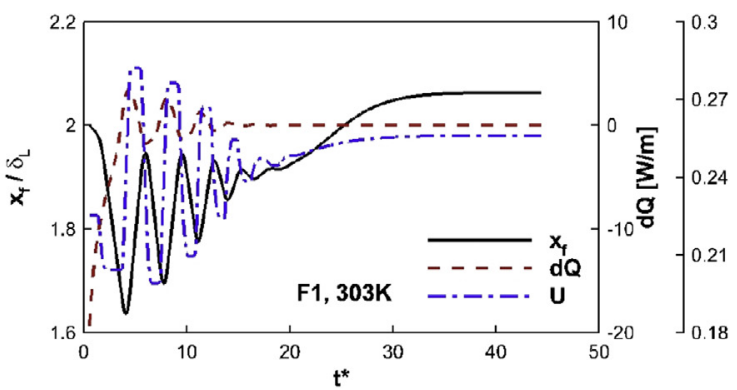

(b)

Fig. 2 - Temporal evolution of the mean standoff distance, $x_{f}$, the total net heat flux, dQ, and inlet velocity, $U$ [m/s], for the methane flames at the burner plate temperature of (a) $T_{p}=368 \mathrm{~K}$ (F1a), and (b) $T_{p}=303 \mathrm{~K}$ (F1b). 


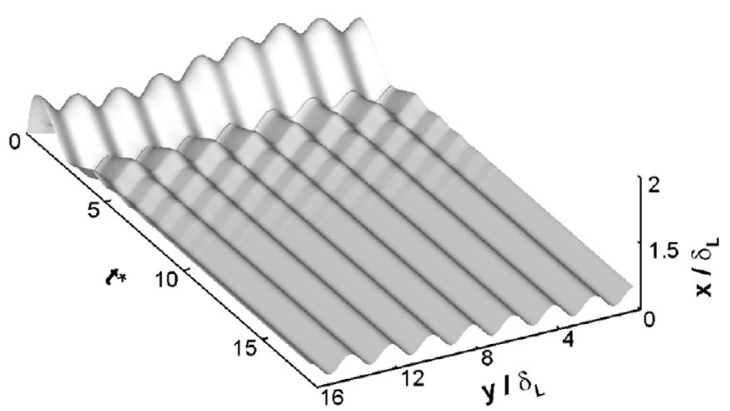

(a)

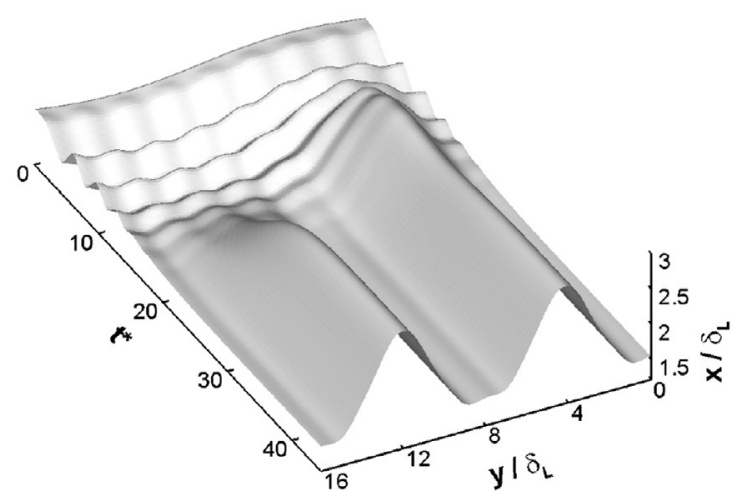

(b)

Fig. 3 - Temporal evolution of the flame front of the methane flames for burner plate temperatures of (a) $T_{p}=368 \mathrm{~K}, \mathrm{~F} 1 \mathrm{a}$ and (b) $\mathrm{T}_{\mathrm{p}}=303 \mathrm{~K}, \mathrm{~F} 1 \mathrm{~b}$.

To further examine the instabilities for the methane flames various Fourier modes of the flame fronts are shown in Fig. 4. The $\mathrm{k}_{1}$ mode is the initial mode superimposed on the flame fronts with $A_{1}=0.1$. For the $T_{p}=368 \mathrm{~K}$ case (F1a), it is seen that the amplitude of mode $k_{1}$ decays directly and becomes zero after $t^{*}=6$. Meanwhile, the $k_{8}$ mode is developing and increases in magnitude rapidly. As $\mathrm{t}^{*}$ increases the flame is moving closer to the burner and all modes except the $\mathrm{k}_{8}$ mode are suppressed. The $k_{8}$ mode becomes steady with an amplitude of about 0.06 . For the $\mathrm{T}_{\mathrm{p}}=303 \mathrm{~K}$ case (F1b, Fig. 4b), it is seen that the $\mathrm{k}_{1}$ mode is amplified first as the flame evolves. When $t^{*}>30$ the $k_{1}$ mode is suppressed while the $k_{2}$ and $k_{4}$ modes are evolving to be the dominant modes. The $\mathrm{k}_{3}$ mode appears in the time interval $10<\mathrm{t}^{*}<25$. These modes are due to the intrinsic flame instability, mainly the hydrodynamic effect [30], which promotes the shorter wavenumber modes supported by the domain. The $\mathrm{k}_{8}$ mode, which is owing to the burner non-uniformity, is noticeable during the evolution of

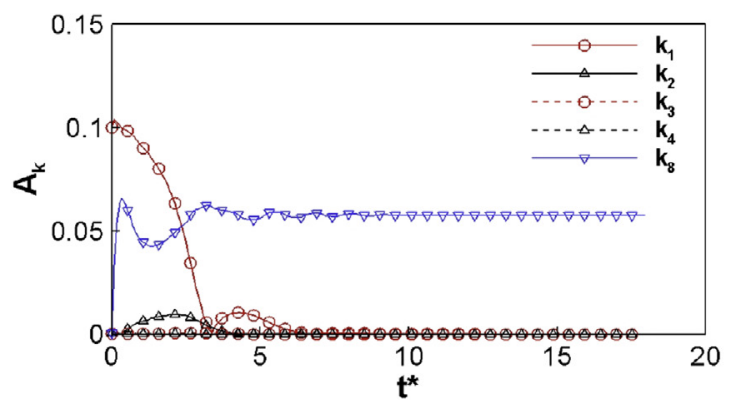

(a)

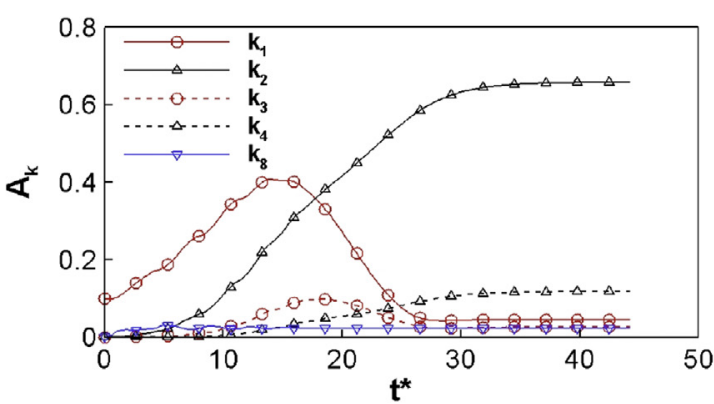

(b)

Fig. 4 - Temporal evolution of the amplitudes of various Fourier modes of the flame front of the methane flames at (a) $\mathrm{T}_{\mathrm{p}}=368 \mathrm{~K}, \mathrm{~F} 1 \mathrm{a}$ and (b) $\mathrm{T}_{\mathrm{p}}=303 \mathrm{~K}, \mathrm{~F} 1 \mathrm{~b}$.

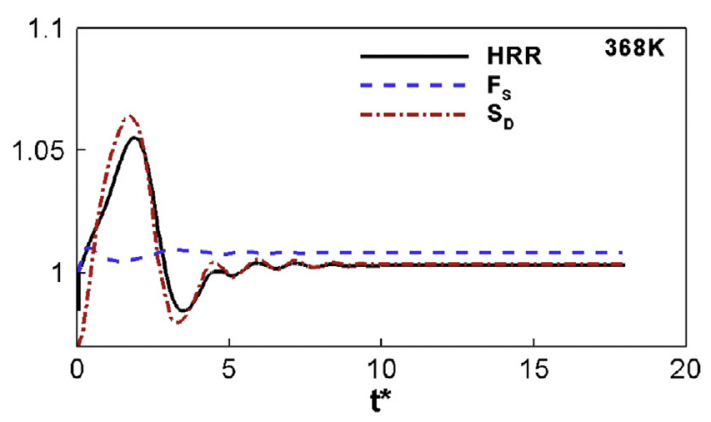

(a)

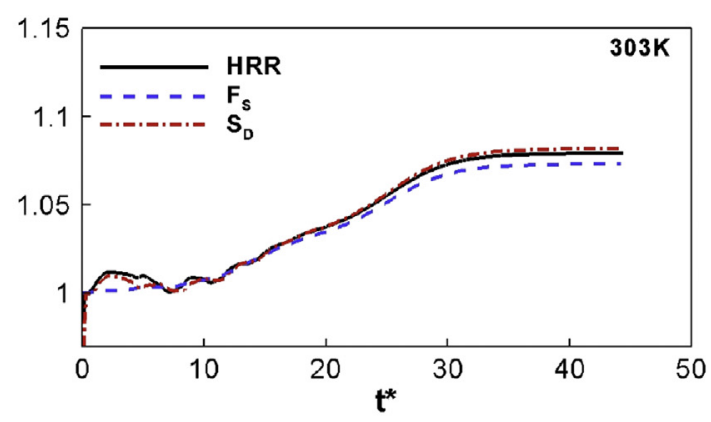

(b)

Fig. 5 - Temporal evolution of the total heat release rate, HRR, flame surface area, $F_{S}$, and flame speed, $S_{D}$, for the methane flames at the burner plate temperature of (a) $T_{p}=368 \mathrm{~K}, \mathrm{~F} 1 \mathrm{a}$ and (b) $T_{p}=303 \mathrm{~K}, \mathrm{~F} 1 \mathrm{~b}$. HRR, $F_{s}$ and $S_{D}$ have been normalized by the corresponding values of the initial planar flames, cf. Eq. (9) and Table 2 for the initial values of these quantities. 
flame instability. The amplitude of the $\mathrm{k}_{8}$ mode is however rather small. In a previous study of the F1b flame [30] a similar cellular structure was observed when the effect of burner holes was neglected. The onset of cellular instability in the F1b flame was shown to be primarily owing to the hydrodynamic instability. Diffusional-thermal instability played a less important role under the F1a and F1b flame conditions. The tendency of burner suppression of flame instability as the burner plate temperature increases is consistent with the experiment [30]. In Fig. 6 of Ref. [30] it was shown that the flame becomes stable as the standoff distance decreases (a result of increasing burner plate temperature). The present
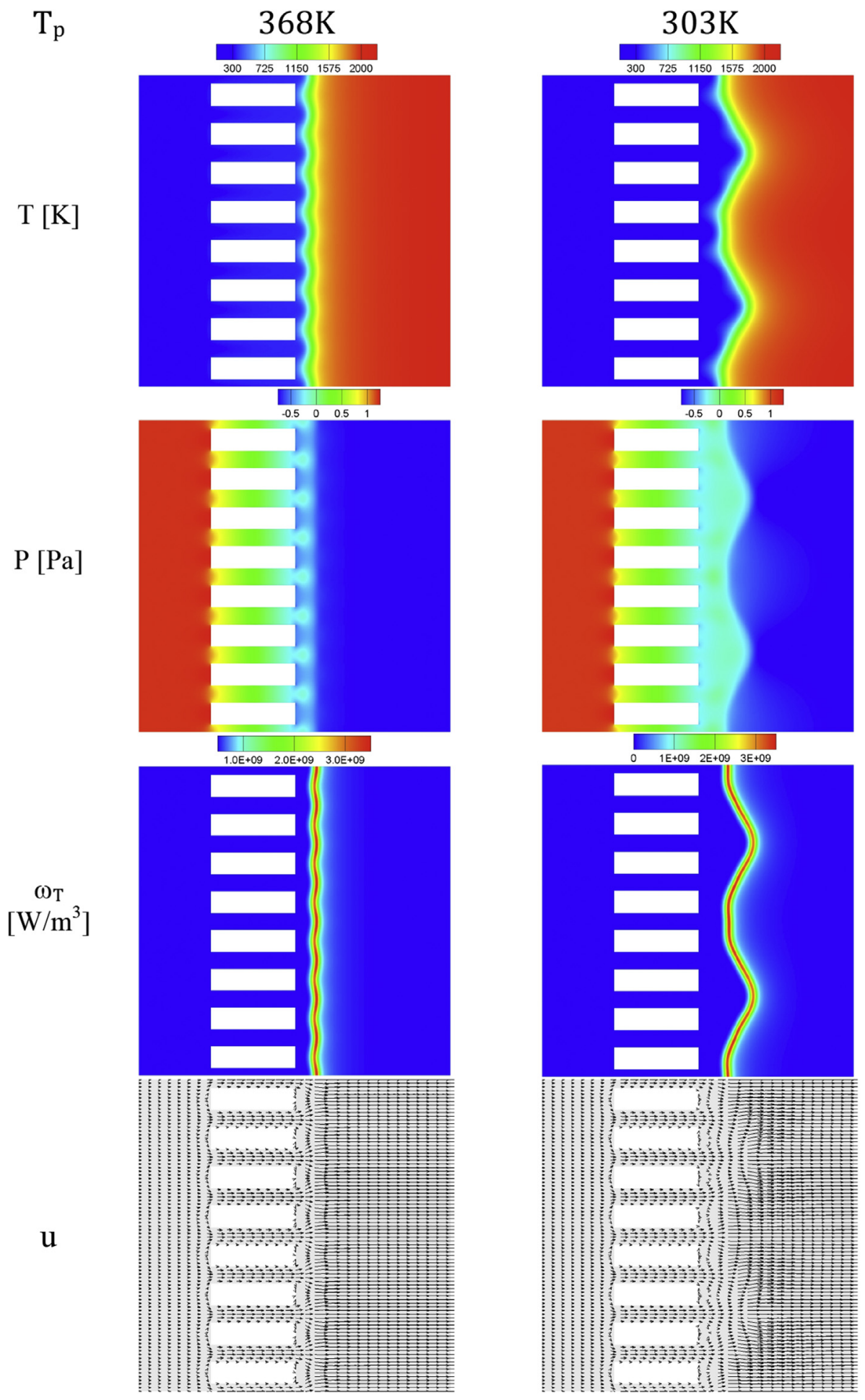

Fig. 6 - Distributions of temperature, T, hydrodynamic pressure, p, local heat release rate, $\omega_{\mathrm{T}}$, and velocity vectors $(\mathrm{u})$ around the burner plate for the methane flames with the burner plate temperature $T_{p}=368 \mathrm{~K}(\mathrm{~F} 1 \mathrm{a})$ and $303 \mathrm{~K}$ (F1b), respectively. 


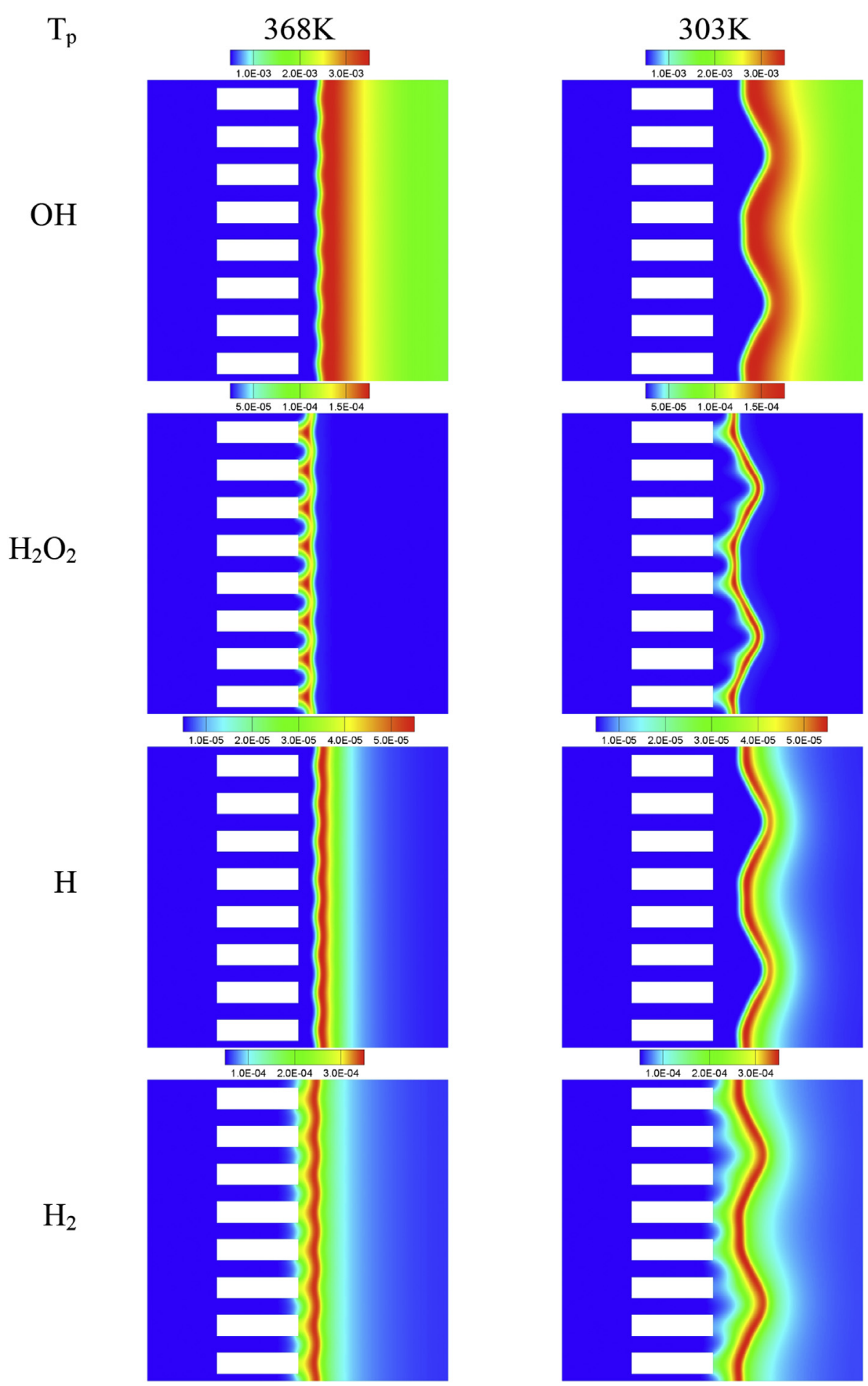

Fig. 7 - Distributions of mass fractions of $\mathrm{OH}, \mathrm{H}_{2} \mathrm{O}_{2}, \mathrm{H}$ and $\mathrm{H}_{2}$ around the burner plate for the methane flames with the burner plate temperature $\mathrm{T}_{\mathrm{p}}=368 \mathrm{~K}(\mathrm{~F} 1 \mathrm{a})$ and $303 \mathrm{~K}(\mathrm{~F} 1 \mathrm{~b})$, respectively.

results agree also very well with the numerical results of Ref. [30], which predicted that F1a is stable whereas flame F1b is cellular.

The impact of flame front wrinkling in flames F1a and F1b (due to burner non-uniformity and flame instability) on the global heat release rate, flame surface area and mean burning velocity is shown in Fig. 5. At the high plate temperature condition $\left(T_{p}=368 \mathrm{~K}, \mathrm{Fla}\right.$, Fig. $\left.5 \mathrm{a}\right)$, the flame front wrinkling is mainly due to the burner flow non-uniformity, and as such the flame surface area is increased only slightly, about $0.8 \%$. The curvature (and flame stretch) caused by the $\mathrm{k}_{8}$ mode is rather low and it leads to a minor increase of the global heat release rate and burning velocity by about $0.3 \%$. For the low plate temperature case $\left(T_{p}=303 \mathrm{~K}, \mathrm{~F} 1 \mathrm{~b}\right.$, Fig. $\left.5 \mathrm{~b}\right)$, the flame wrinkling is owing to intrinsic flame instability; with the dominant $\mathrm{k}_{2}$ mode the wavelength of the wrinkling flame surface is half 
the domain width. This has caused a larger increase of the flame surface area, about 7\%; accordingly, the global heat release rate and the mean burning velocity are increased by about $8 \%$. It can be concluded that the effect of the flow nonuniformity generated by the burner holes on the burning velocity is not significant. This conclusion is consistent with the earlier numerical study of de Goey et al. [29] where only one hole was considered.

\section{Analysis of the effect of burner non-uniformity (flames F1a and $\mathrm{F} 1 \mathrm{~b}$ )}

To investigate the effect of the burner on flames F1a and F1b the distributions of temperature, hydrodynamic pressure, heat release rate, mass fractions of several key species, and velocity vector fields are shown in Figs. 6 and 7. For the $\mathrm{T}_{\mathrm{p}}=368 \mathrm{~K}$ case (F1a) the $2 \mathrm{D}$ fields are taken at $\mathrm{t}^{*}=17$; for the low plate temperature case, $\mathrm{T}_{\mathrm{p}}=303 \mathrm{~K}(\mathrm{~F} 1 \mathrm{~b})$, the 2D fields are taken at $t^{*}=44$. As seen in Figs. $2-5$ at these instances of time the flame fronts have experienced a long time evolution and rather stationary flame shapes are developed. For both cases the regions with $\mathrm{H}$ and $\mathrm{OH}$ radicals as well as the heat release rate are not attached to the burner walls; thus, quenching of radicals $\mathrm{H}$ and $\mathrm{OH}$ at the wall is not significant. For the $\mathrm{T}_{\mathrm{p}}=368 \mathrm{~K}$ case, the mean standoff distance is small; the flame is close to the wake region of the burner plate wall. The preheat zone (cf. $\mathrm{T}, \mathrm{H}_{2} \mathrm{O}_{2}$ and $\mathrm{H}_{2}$ distributions) are seen to attach the wall. The pressure is fairly non-uniform in front of the flame. It is clear that each hole of the burner plate has generated a wrinkle cell on the flame front. In the low plate temperature case $\left(\mathrm{F} 1 \mathrm{~b}, \mathrm{~T}_{\mathrm{p}}=303 \mathrm{~K}\right)$, the mean flame is farther away from the burner and the effect of burner walls can be noticed only in some part of the flame; the preheat zone in the close-to-burner part of the flame is attached to the walls (see $\mathrm{T}, \mathrm{H}_{2} \mathrm{O}_{2}, \mathrm{H}_{2}$ distributions); however, the major part of the flame is not affected by the burner walls.

Note that in Fig. 6 for clarity the velocity vectors are shown on a coarse grid. On the fine grid detailed distribution of the velocity vector and temperature in a zoomed region around the third burner plate hole is shown in Figs. 8 and 9 (the holes are countered from top to bottom in Figs. 6 and 7). In both the high and low burner plate temperature cases the velocity vectors in the hole show a typical parabolic profile. The gas in the hole is heated up as it is passing through the hole. For the $\mathrm{T}_{\mathrm{p}}=368 \mathrm{~K}$ case (F1a) the temperature field is symmetric with respect to the axis of the hole; for the $T_{p}=303 \mathrm{~K}$ case $(\mathrm{F} 1 \mathrm{~b})$ an asymmetric temperature distribution is shown. This is clearly due to the large-scale cellular shape of the flame front in the latter case.

As will be discussed later, in the preheat zone attached to the wall heat is transferred from the flame to the wall whereas the gas receives heat when passing through the holes. The net heat flux is maintained to be zero when the mean standoff distance is adjusted.

\section{Effect of Lewis number (flames F2 $a$ and F2b)}

To investigate the diffusional-thermal effect on the flame instability lean $\mathrm{H}_{2} / \mathrm{O}_{2} / \mathrm{N}_{2}$ flames are considered, i.e. flames $\mathrm{F} 2 \mathrm{a}$ and $\mathrm{F} 2 \mathrm{~b}$ in Table 2. Similar to the F1a and F1b flames two

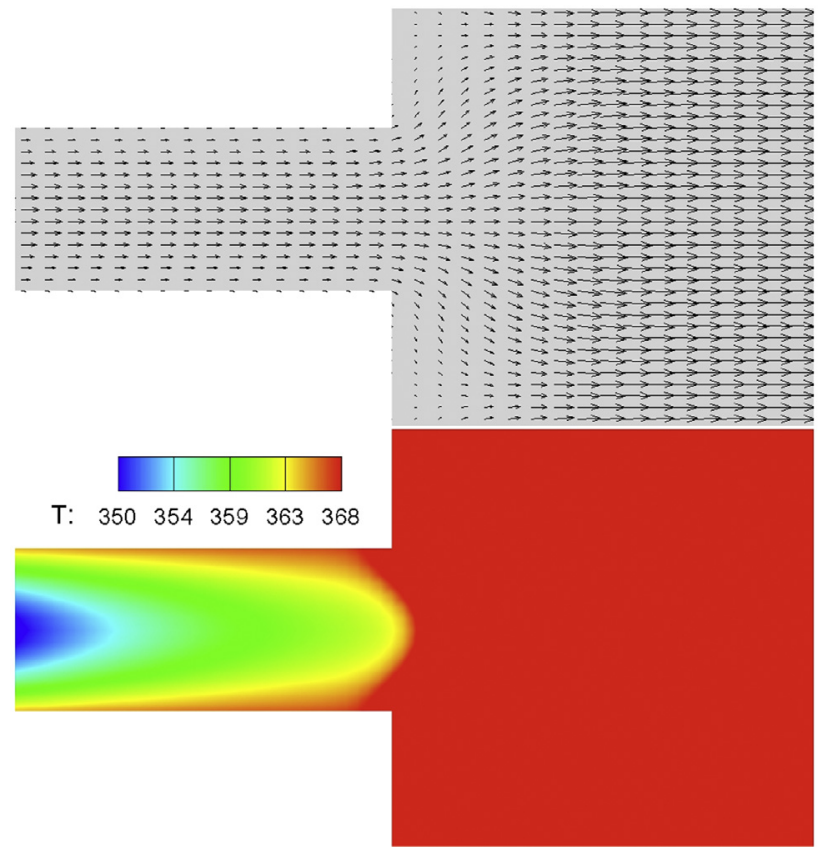

Fig. 8 - Velocity vector and temperature in a zoomed region around the burner plate for flame F1a with the burner plate temperature $T_{p}=368 \mathrm{~K}$.

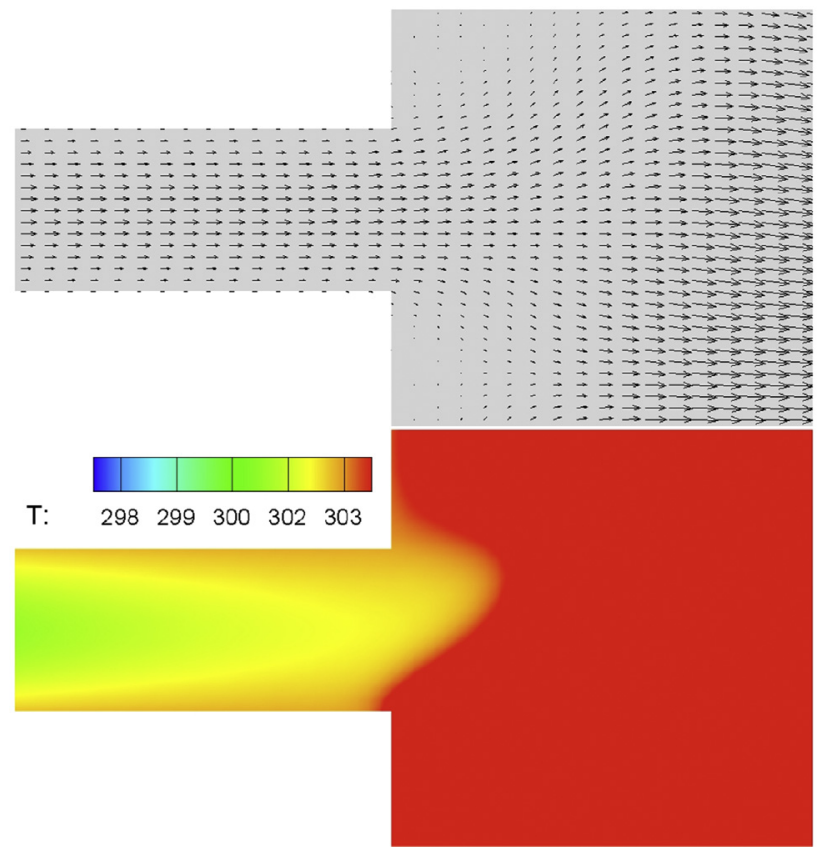

Fig. 9 - Velocity vector and temperature in a zoomed region around the third hole of the burner plate (from top) for flame $\mathrm{F} 1 \mathrm{~b}$ with the burner plate temperature $T_{p}=303 \mathrm{~K}$.

burner plate temperatures are examined, $\mathrm{T}_{\mathrm{p}}=303 \mathrm{~K}$ and $368 \mathrm{~K}$. By adjusting the inflow velocity the mean standoff distance is maintained at $\mathrm{x}_{\mathrm{f}}=2.06$ and 1.07 respectively for $\mathrm{T}_{\mathrm{p}}=303 \mathrm{~K}$ and $368 \mathrm{~K}$. These standoff distances are chosen to allow for a comparison between the methane flames and the hydrogen flames at the same burner plate temperature and standoff 


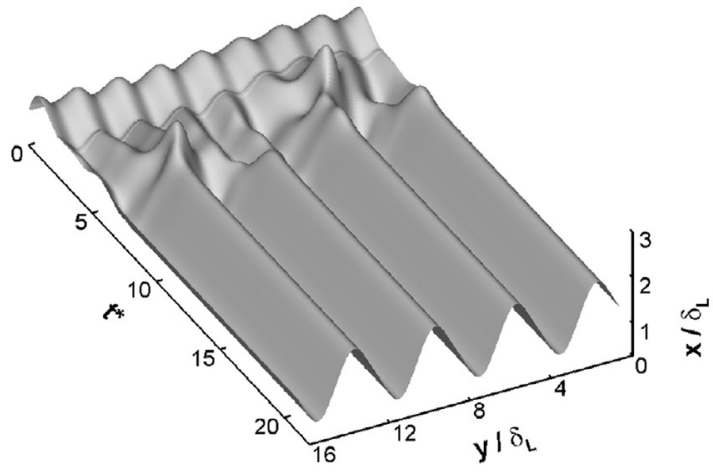

(a)

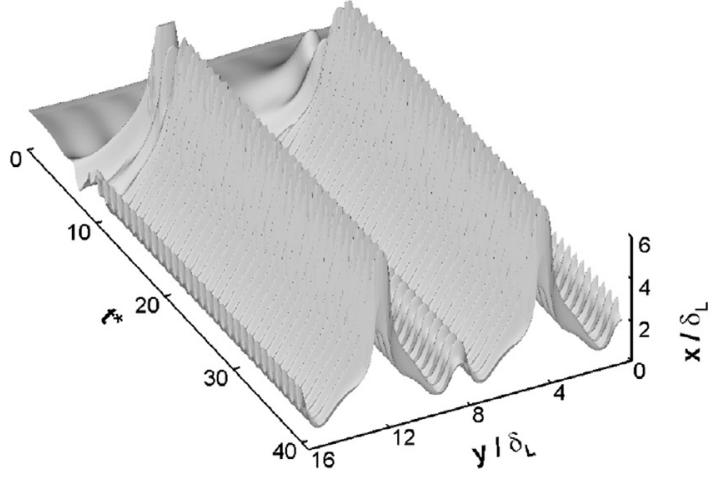

(b)

Fig. 10 - Temporal evolution of the flame front of the hydrogen flames at various burner plate temperatures and standoff distances, (a) F2a, $T_{p}=368 \mathrm{~K}, x_{f}=1.07$, and (b) F2b, $T_{p}=303 \mathrm{~K}, x_{f}=2.06$.

distance conditions. These standoff distances generate a zero net heat flux for flames F1a and F1b. For flame F2 with these standoff distances a net heat flux is transferred from the gas to the walls, i.e., $d Q=177-512 \mathrm{~W} / \mathrm{m}$ for the $\mathrm{T}_{\mathrm{p}}=303 \mathrm{~K}$ case due to the oscillation of the flame, and $151 \mathrm{~W} / \mathrm{m}$ for the $\mathrm{T}_{\mathrm{p}}=368 \mathrm{~K}$ case. To generate a zero net heat flux the standoff distance needs to be increased in both cases. This leads to a more unstable flame. We will discuss later the behavior of flames F2a and $\mathrm{F} 2 \mathrm{~b}$ under adiabatic condition.

As seen in Figs. 3 and 10, with the same standoff distance, flames F2a and F2b are much more unstable than flames F1a and $\mathrm{F} 1 \mathrm{~b}$. With $\mathrm{T}_{\mathrm{p}}=368 \mathrm{~K}$ the intrinsic instability is suppressed

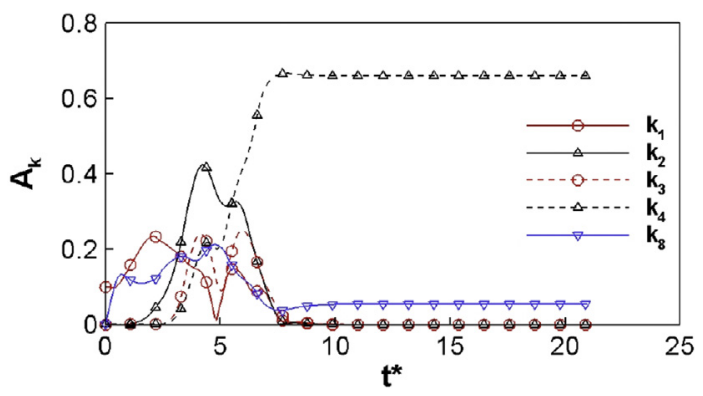

Fig. 11 - Temporal evolution of the amplitudes of various Fourier modes of the flame front of flame F2a at $T_{p}=368 \mathrm{~K}$, and mean standoff distance $x_{f}=1.07$.

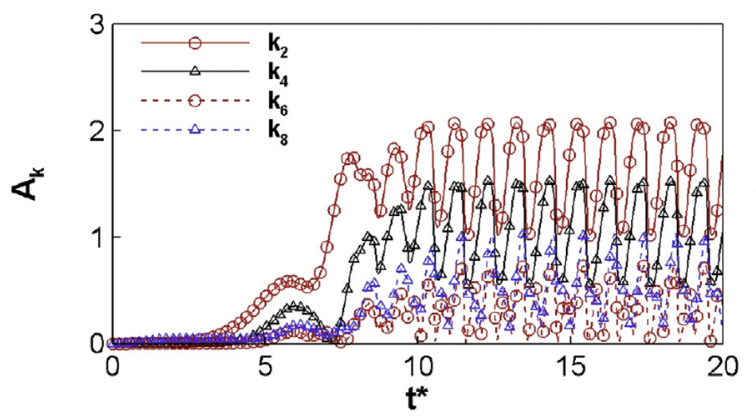

completely by the burner in flame F1a but it is not suppressed in flame F2a. As seen in Fig. 11, after $t^{*}>10$, the flame shape becomes stable and a four-cell structure is formed on it. That is, the dominant Fourier mode of the flame front function is the $\mathrm{k}_{4}$ mode. The $\mathrm{k}_{8}$ mode, which is a result of burner flow non-uniformity, can also be noticed although with a relatively lower amplitude.

With $\mathrm{T}_{\mathrm{p}}=303 \mathrm{~K}$, flame $\mathrm{F} 2 \mathrm{~b}$ shows much stronger dynamic temporal evolution than that in flame F1b. This can be further illustrated in the temporal evolution of the various Fourier modes of the flame front function. Comparing flames F1b and $\mathrm{F} 2 \mathrm{~b}$ at $\mathrm{T}_{\mathrm{p}}=303 \mathrm{~K}$, cf. Figs. $4 \mathrm{~b}$ and 12 , one can see that the $\mathrm{k}_{2}$ mode is the most important one in both flames. However, in the hydrogen flame $\mathrm{F} 2 \mathrm{~b}$ the $\mathrm{k}_{4}$ and $\mathrm{k}_{6}$ modes are also significant. These additional modes are thus due to diffusionalthermal instability. The amplitudes of all modes shown in Fig. 12 fluctuate rapidly in time around their corresponding mean values, indicating that the cellular structures evolve rapidly in time. When $t^{*}>15$ the mean cellular structure becomes statistically stationary, and all of the odd modes are suppressed totally. Similar to flame F1b, the effect of the burner plate holes on the flame front wrinkling can be observed in Fourier mode $\mathrm{k}_{8}$, with its amplitude smaller than those large wavelength modes.

Snapshots of 2D distributions of local heat release rate and $\mathrm{OH}$ radicals are displayed in Fig. 13 for the final steady state of flame $\mathrm{F} 2 \mathrm{a}$ at $\mathrm{T}_{\mathrm{p}}=368 \mathrm{~K}$ with $\mathrm{x}_{\mathrm{f}}=1.07$, and in Fig. 14 for flame

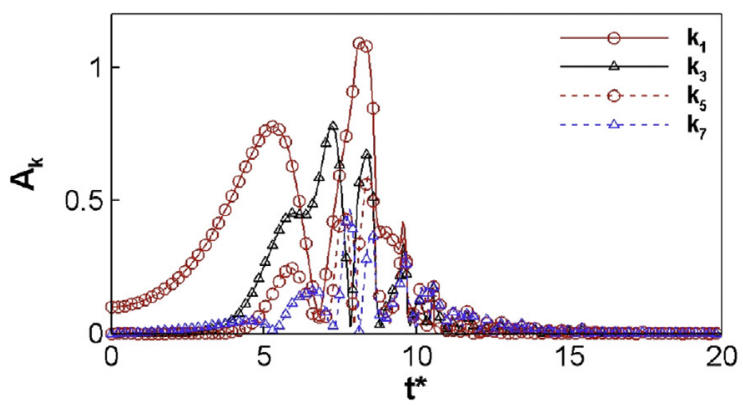

Fig. 12 - Temporal evolution of the amplitudes of various Fourier modes of the flame front of flame $F 2 b$ at $T_{p}=303 \mathrm{~K}$, and mean standoff distance $x_{f}=2.06$. 


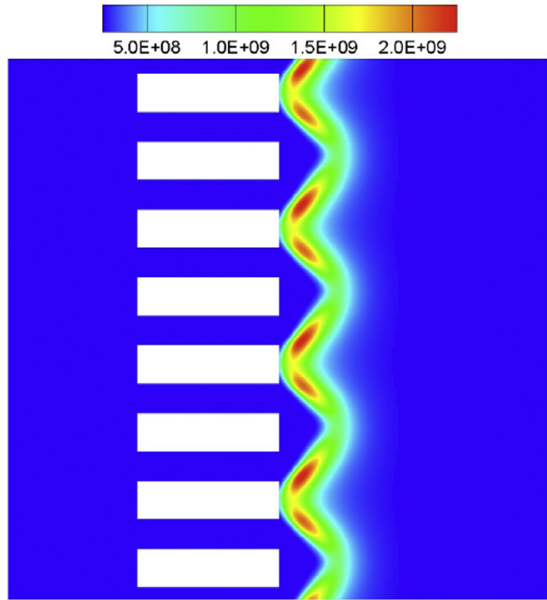

(a)

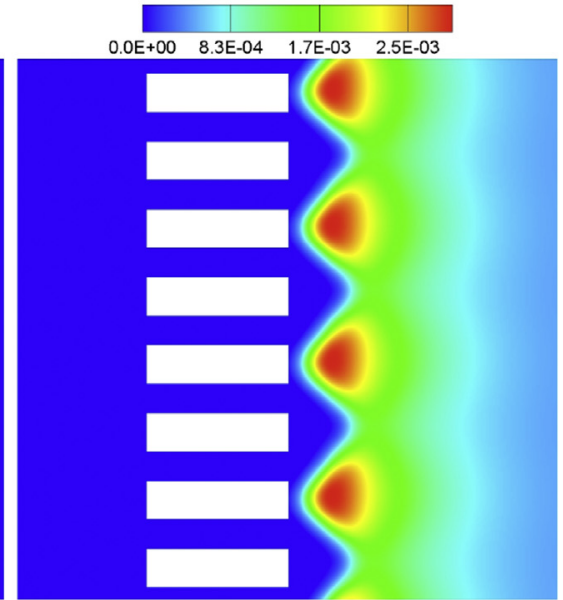

(b)

Fig. 13 - Distributions of local heat release rate (a) and OH mass fraction (b) in flame F2a at the steady state, under condition $T_{p}=368 \mathrm{~K}$, with the mean standoff distance $x_{f}=1.07$.

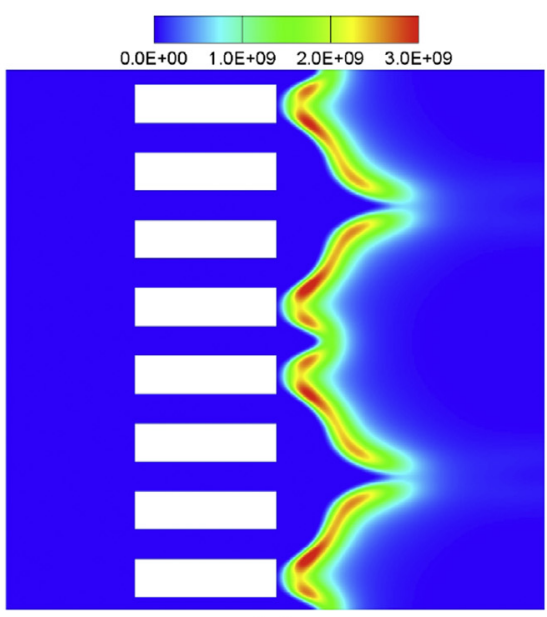

(a)

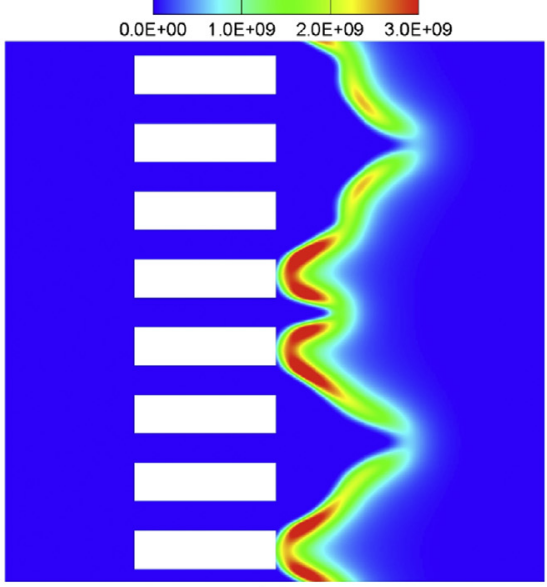

(c)

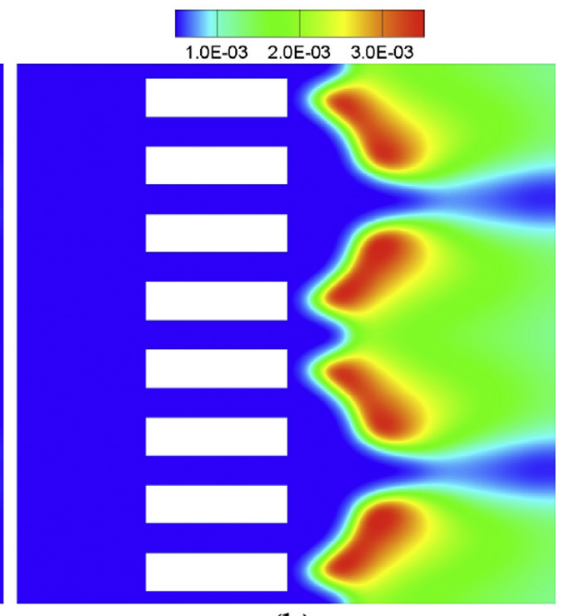

(b)

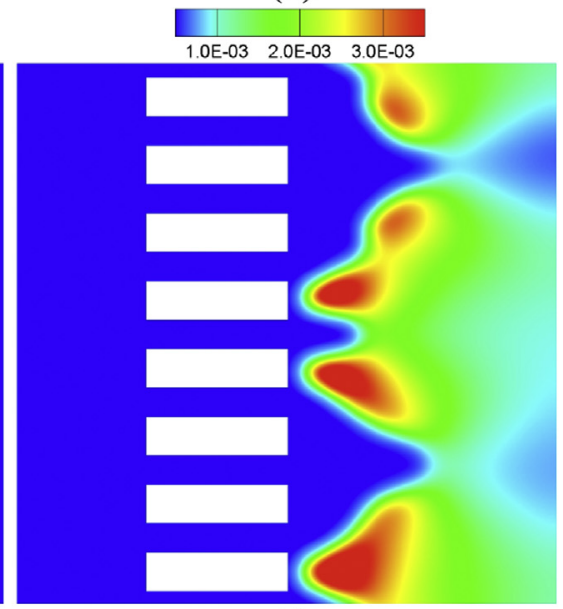

(d)

Fig. 14 - Distributions of local heat release rate $(a, c)$ and OH mass fraction $(b, d)$ in flame F2b at two of instances of time, $t^{*}=32(a, b)$ and $t^{*}=35(c, d)$, under condition $T_{p}=303 \mathrm{~K}$, with the mean standoff distance $x_{f}=2.06$. 


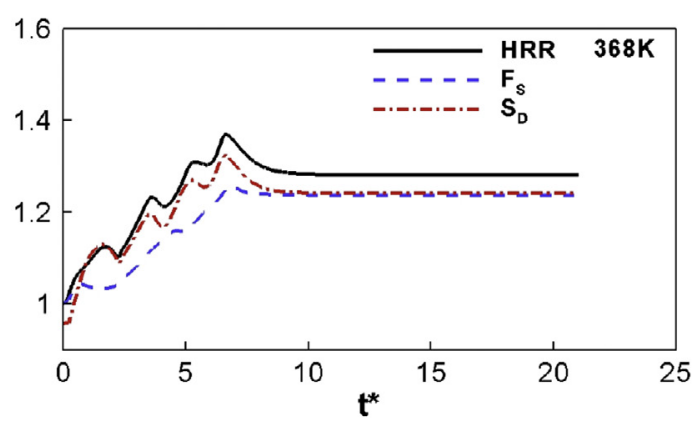

(a)

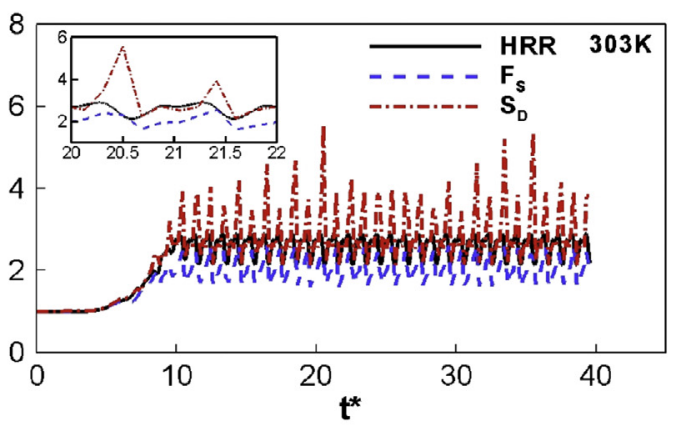

(b)

Fig. 15 - Temporal evolution of the total heat release rate, HRR, flame surface area, $F_{S}$, and flame speed, $S_{D}$, for the hydrogen flames at the burner plate temperature of (a) $T_{p}=368 \mathrm{~K}, \mathrm{~F} 2 \mathrm{a}$, and (b) $\mathrm{T}_{\mathrm{p}}=303 \mathrm{~K}, \mathrm{~F} 2 \mathrm{~b}$. HRR, $\mathrm{F}_{\mathrm{s}}$ and $\mathrm{S}_{\mathrm{D}}$ have been normalized by the corresponding values of the initial planar flame, cf. Eq. (9) and Table 2 for the initial values of these quantities.

$\mathrm{F} 2 \mathrm{~b}$ at $\mathrm{T}_{\mathrm{p}}=303 \mathrm{~K}$ with $\mathrm{x}_{\mathrm{f}}=2.06$. At the latter low burner plate temperature condition flame $\mathrm{F} 2 \mathrm{~b}$ does not reach to a steady state; Fig. 14 shows snapshots at two instances of time after $t^{*}>30$. One can observe the large wavelength modes as well as the wrinkles due to the burner holes. It appears that both flow non-uniformity from the burner and intrinsic flame instability contribute to the flame front wrinkling. The heat release rate and the $\mathrm{OH}$ radicals are much more inhomogeneous along the flame fronts of F2a and F2b than those of flames F1a and F1b, cf. Figs. 6, 7, 13 and 14, which is clearly the reason of the enhanced flame instability in the hydrogen flames F2a and F2b.

Finally, one can see from Fig. 15 that the cellular instability and burner flow non-uniformity can lead to a significant increase in the flame surface area, total heat release rate and mean burning velocity. For the $\mathrm{T}_{\mathrm{p}}=368 \mathrm{~K}$ case (F2a), the mean burning velocity increases by about $25 \%$ when compared with its planar one. For the $\mathrm{T}_{\mathrm{p}}=303 \mathrm{~K}$ case $(\mathrm{F} 2 \mathrm{~b})$, the mean burning velocity can be more than tripled.

In the present study the standoff distances of the hydrogen flames F2a and F2b have been kept the same as that of the methane flames to allow for identification of the effect of diffusional-thermal instability. By keeping the same standoff distances as the methane flames the hydrogen flames F2a and $\mathrm{F} 2 \mathrm{~b}$ have a net heat loss from the flames to the burner wall, which has two consequences. First, it decreases the flame temperature and thereby the density variation across the flame. The hydrodynamic instability is partly suppressed. Second, by allowing for heat loss to the burner wall the standoff distance can be kept lower, thus the burner can suppress the development of the flame instability. This implies that under adiabatic conditions flames $\mathrm{F} 2 \mathrm{a}$ and $\mathrm{F} 2 \mathrm{~b}$ would be more pertaining to flame instability. One can conclude that, for the hydrogen flames F2a and F2b, the uncertainty in the measurements of adiabatic laminar burning velocity using the heat-flux method is higher than that of the flames under heat loss and small standoff distance conditions.

\section{Effect of burner plate on accuracy of heat-flux method}

As shown in Fig. 5a, with a burner plate temperature of $368 \mathrm{~K}$ flame F1a has a rather low degree of wrinkling $(<1 \%$ increase of flame surface area), with roughly the same values of total heat release rate and the mean flame speed as those from the planar freely propagating one, which has verified the principle of the heat-flux method. To understand the heat flux burner in details, we compare results of flame F1a with the corresponding planar flame solution.

Fig. 16 presents profiles of local heat flux dq in 3D form around one wall of flame F1a with $\mathrm{T}_{\mathrm{p}}=368 \mathrm{~K}$ at $\mathrm{t}^{*}=17$ (after the flame is stabilized). In general, dq along the wall surface is non-zero, while the total net heat flux is zero. It is obvious that heat loss (positive dq) from the flame to the wall occurs on the downstream surface of the plate, where the maximum value is at the center of it. The unburned mixture receives heat from the upstream surface of the plate and the internal surface in the hole. The latter part contributes about half of the heat transferred from the wall to the gas mixture.

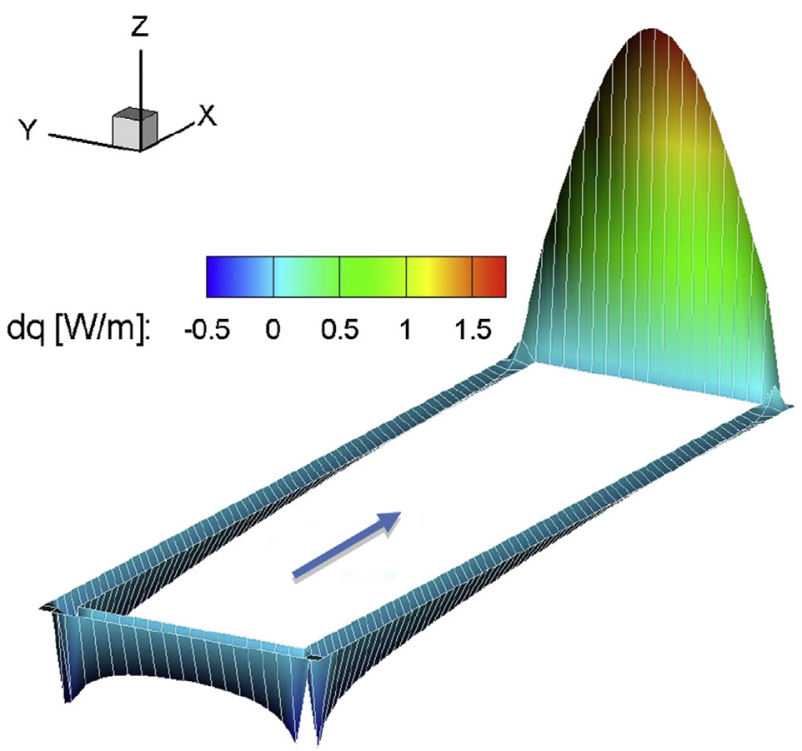

Fig. 16 - Profiles of local heat flux dq (z axis) around one wall ( $x$-y plane) taken at the steady state of flame F1a with $T_{p}=368 \mathrm{~K}$ at $t^{*}=17$. The arrows indicate the flow direction; the height of the profiles indicates the magnitude of $\mathrm{dq}$. 
Fig. 17 shows the scattering of temperature and local heat release rate along streamwise direction for flame F1a with $\mathrm{T}_{\mathrm{p}}=368 \mathrm{~K}$ after the flame is stabilized $\left(\mathrm{t}^{*}=17\right)$. The data are based on all points in the computational domain. The inset plot in Fig. 17a shows the temperature profile along the entire streamwise domain. It is seen that with zero net heat flux the local heat release rate scatters around the solution of $1 \mathrm{D}$ planar adiabatic flame. The scattering of temperature and heat release rate in the flame region is partly owing to the spatial wrinkling of the flame and partly owing to the variation of temperature along the lateral direction inside the burner plate holes.

Fig. 18 shows the displacement speed of the flame $\left(\mathrm{S}_{\mathrm{d}, \mathrm{u}}\right)$ along the flame fronts for flame F1a at $t^{*}=17$ and flame F1b at $\mathrm{t}^{*}=44$. For the $\mathrm{T}_{\mathrm{p}}=368 \mathrm{~K}$ case $(\mathrm{F} 1 \mathrm{a})$, the flame is closer to the burner plate and the net heat transfer between the burner plate and the flame is zero. Only the $\mathrm{k}_{8}$ mode is observed at

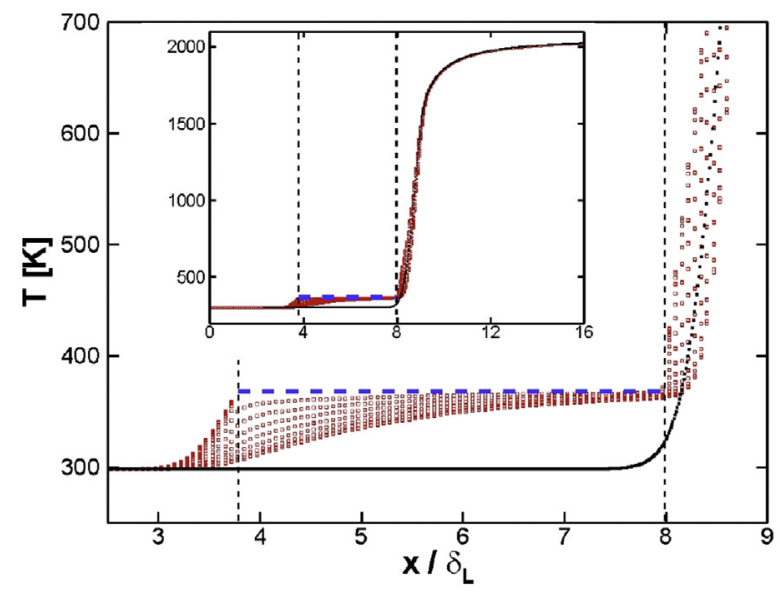

(a)

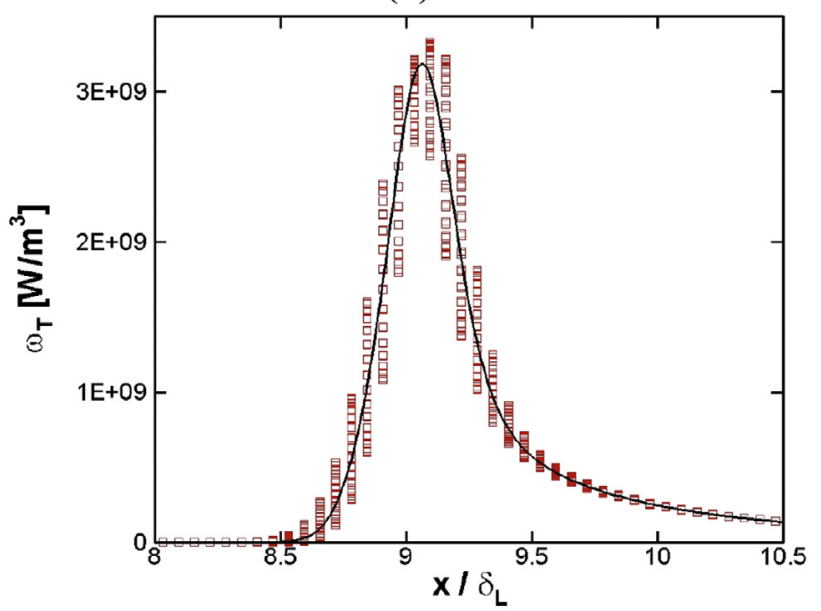

(b)

Fig. 17 - Scattering (red symbols) of (a) temperature and (b) local heat release rate $\left(\omega_{\mathrm{T}}\right)$ along the streamwise direction of flame F1a with $T_{p}=368 \mathrm{~K}$ at $t^{*}=17$. Black lines denote the 1D flame solution. In (a) the horizontal dashed line denotes $T_{p}=368 \mathrm{~K}$, whereas the two vertical dashed lines denote the burner plate location. (For interpretation of the references to color in this figure legend, the reader is referred to the web version of this article.)

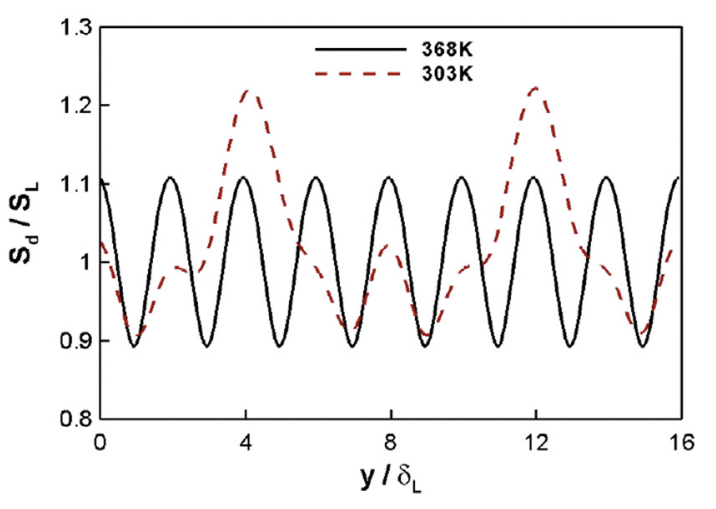

Fig. 18 - Distributions of normalized local displacement speed of flame, $S_{d, u} / S_{L}$, along the flame fronts for flame $F 1 a$ $\left(T_{p}=368 \mathrm{~K}\right)$ at $t^{*}=17$ and for flame $F 1 b\left(T_{p}=303 \mathrm{~K}\right)$ at $\mathbf{t}^{*}=44$.

the flame surface. It appears that the flame segments downstream of the jet flow (where the gas has been heated up) have enhanced the local heat release rate and the local displacement speed, whereas the segments downstream of the wall wakes (where heat is transferred from the flame to the walls) have suppressed the local heat release rate and the local displacement velocity. However, the averaged $\mathrm{S}_{\mathrm{d}, \mathrm{u}}$ along the front is roughly the same as $\mathrm{S}_{\mathrm{L}}$. For the $\mathrm{T}_{\mathrm{p}}=303 \mathrm{~K}$ case (F1b), it is obvious that the two large cells at the flame front (cf. Figs. 6 and 7) have resulted in locally enhanced heat release rate and locally higher displacement speed. The averaged $\mathrm{S}_{\mathrm{d}, \mathrm{u}}$ along the front is therefore higher than that of $\mathrm{T}_{\mathrm{p}}=368 \mathrm{~K}$ case.

In the experiments using the heat-flux burner, it is easy to observe whether large scale flame wrinkles exist; for the cases without large scale wrinkles the heat-flux burner offers a good tool to measure adiabatic unstretched laminar burning velocity with a high accuracy. The heat-flux burner holes do affect the local heat release rate and local displacement speed; however, as an average of the fluctuations the mean heat release rate and the mean burning velocity obtained using the method are in good agreement with those of planar flames. The method is nevertheless challenged when measuring the laminar burning velocity of flames that have a tendency to develop into cellular instabilities, e.g. lean hydrogen/air flames.

\section{Conclusion}

Flame stabilization and heat transfer of laminar premixed flames for $\mathrm{CH}_{4} / \mathrm{O}_{2} / \mathrm{CO}_{2}$ and $\mathrm{H}_{2} / \mathrm{O}_{2} / \mathrm{N}_{2}$ mixtures anchored to a heat-flux burner are investigated using a high-order numerical method with detailed chemical kinetic mechanisms and detailed transport properties, in order to elucidate the effects of the flow and mixture inhomogeneity generated by the burner plate holes on flame instability. The results show that the burner plate holes can cause flame front wrinkling. The wrinkling scale is of the hole diameter, which in the present flames is shown as the $k_{8}$ mode. The amplitude of this mode is 
rather small and it does not vary much with time. For the methane flames with higher burner plate temperature, the intrinsic flame instability is suppressed by the burner. The non-uniformity of the burner plate holes can only cause a little difference in the mean burning velocity and the total heat release rate owing to the rather small increase of flame area. When the burner temperature is low, the flame can develop to a large-scale cellular shape owing to the hydrodynamic instability mechanism and the mean burning velocity increases. For the hydrogen flames, the flame is much easier to develop to large-scale cells, with local extinction in the concave part of the flame. This is understood as a result of diffusional-thermal instability. The large-scale cells (small wavenumber modes) are not directly affected by the flow and the temperature inhomogeneity generated by the burner plate holes. The mean burning velocity can be much higher when compared with the planar flame ones for the hydrogen flames.

\section{Acknowledgments}

This work was sponsored by the Swedish Research Council (VR), the Competence Centre for Combustion Process at Lund University (KCFP), and the National Centre for Combustion Science and Technology (CeCOST). J.F. Yu was supported by the China Scholarship Council (CSC) and the National Natural Science Foundation of China (No. 51406233). The computations were performed using the computer facilities provided by the Swedish National Infrastructures for Computing (SNIC).

\section{R E F E R E N C E S}

[1] Vagelopoulos CM, Egolfopoulos FN, Law CK. Further considerations on the determination of laminar flame speeds with the counterflow twin-flame technique. Proc Combust Inst 1994;25:1341-7.

[2] Chen Z, Burke MP, Ju YG. Effects of Lewis number and ignition energy on the determination of laminar flame speed using propagating spherical flames. Proc Combust Inst 2009;32:1253-60.

[3] Powling J. A new burner method for the determination of low burning velocities and limits of inflammability. Fuel 1949;28(2):25-8.

[4] Botha JP, Spalding DB. The laminar flame speed of propane/ air mixtures with heat extraction from the flame. Proc Roy Soc Lond A 1954;225:71-96.

[5] Patnaik G, Kailasanath K. Numerical simulations of burnerstabilized hydrogen-air flames in microgravity. Combust Flame 1994;99(2):247-53.

[6] Landau L. On theory of slow combustion. Acta Physicochim USSR 1944;19:77-85.

[7] Darrieus G. Propagation d'un front de flame. La Tech Mod 1938.

[8] Matalon M, Cui C, Bechtold JK. Hydrodynamic theory of premixed flames: effects of stoichiometry, variable transport coefficients and arbitrary reaction orders. J Fluid Mech 2003;487:179-210.
[9] Barenblatt GI, Zeldovich YB, Istratov AG. On diffusionalthermal stability of a laminar flame. J Appl Mech Technol Phys 1962;4:21-6.

[10] Sivashinsky GI. Diffusional-thermal theory of cellular flames. Combust Sci Technol 1977;15:137-46.

[11] Yuan J, Ju Y, Law CK. Coupled hydrodynamic and diffusionalthermal instabilities in flame propagation at subunity Lewis numbers. Phys Fluids 2005;17:1-10.

[12] Kadowaki S, Suzuki H, Kobayashi H. The unstable behavior of cellular premixed flames induced by intrinsic instability. Proc Combust Inst 2005;30:169-76.

[13] Sharpe GJ, Falle SAEG. Nonlinear cellular instabilities of planar premixed flames: numerical simulations of the reactive Navier-Stokes equations. Combust Theory Model 2006;10:483-514.

[14] Sharpe GJ, Falle SAEG. Numerical simulations of premixed flame cellular instability for a simple chain-branching model. Combust Flame 2011;158:925-34.

[15] Rastigejev Y, Matalon M. Numerical simulation of flames as gasdynamic discontinuities. Combust Theory Model 2006;10(3):459-81.

[16] Rastigejev Y, Matalon M. Nonlinear evolution of hydrodynamically unstable premixed flames. J Fluid Mech 2006;554:371-92.

[17] Altantzis C, Frouzakis CE, Tomboulides AG, Kerkemeier SG, Boulouchos K. Detailed numerical simulations of intrinsically unstable two-dimensional planar lean premixed hydrogen/air flames. Proc Combust Inst 2011;33:1261-8.

[18] Gcrar JF, Bell JB, Day MS. The Soret effect in naturally propagating, premixed, lean, hydrogen-air flames. Proc Combust Inst 2009;32:1173-80.

[19] Yuan J, Ju Y, Law CK. Pulsating and hydrodynamic instabilities at large Lewis numbers. Combust Flame 2006;144:386-97.

[20] Yu JF, Yu R, Bai XS. Numerical simulation of flame instability in lean $\mathrm{H}_{2}$ /air mixtures. In: Seventh mediterranean combustion symposium, Chia Laguna, Cagliari, Sardinia, Italy; September 11-15, 2011.

[21] Buckmaster J. Stability of the porous plug burner flame. SIAM J Appl Math 1983;43:1335-49.

[22] Kurdyumov VN, Matalon M. The porous-plug burner: flame stabilization, onset of oscillation, and restabilization. Combust Flame 2008;153:105-18.

[23] Kurdyumov VN, Sanchez-Sanz M. Influence of radiation losses on the stability of premixed flames on a porous-plug burner. Proc Combust Inst 2013;34:989-96.

[24] Joulin G. Flame oscillations induced by conductive losses to a flat burner. Combust Flame 1982;46:271-82.

[25] de Goey LPH, van Maaren A, Quax RM. Stabilization of adiabatic premixed laminar flames on a flat flame burner. Combust Sci Technol 1993;92:201-7.

[26] van Maaren A, Thung DS, de Goey LPH. Measurement of flame temperature and adiabatic burning velocity of methane/air mixtures. Combust Sci Technol 1994;96:327-44.

[27] van Maaren A, de Goey LPH. Combust. Stretch and the adiabatic burning velocity of methane- and propane-air flames. Sci Technol 1994;102:309-14.

[28] Konnov AA, Dyakov IV. Experimental study of adiabatic cellular premixed flames of methane (ethane, propane), oxygen, carbon dioxide mixtures. Combust Sci Technol 2007;179:747-65.

[29] de Goey LPH, Somers LMT, Bosch WMML, Mallens RMM. Modeling of the small scale structure of flat burner-stabilized flames. Combust Sci Technol 1995;104:387-400.

[30] Yu JF, Yu R, Fan XQ, Christensen M, Konnov AA, Bai XS. Onset of cellular flame instability in adiabatic $\mathrm{CH}_{4} / \mathrm{O}_{2} / \mathrm{CO}_{2}$ and $\mathrm{CH}_{4}$ /air laminar premixed flames stabilized on a flatflame burner. Combust Flame 2013;160:1276-86. 
[31] Yu R, Yu JF, Bai XS. An improved high-order scheme for DNS of low Mach number turbulent reacting flows based on stiff chemistry solver. J Comp Phys 2012;23:5504-21.

[32] Carlsson H, Yu R, Bai XS. Direct numerical simulation of lean premixed $\mathrm{CH}_{4} /$ air and $\mathrm{H}_{2}$ /air flames at high Karlovitz numbers. Int J Hydrogen Energy 2014;39:20216-32.

[33] Gullbrand J, Bai XS, Fuchs L. High-order Cartesian grid method for calculation of incompressible turbulent flows. Int J Numer Meth Fluids 2001;36:687-709.

[34] Jiang GS, Shu CW. Efficient implementation of weighted ENO schemes. J Comp Phys 1996;126:202-28.
[35] Hermanns RTE. Laminar burning velocities of methane-hydrogen-air mixtures [Ph.D. thesis]. Technische Universiteit Eindhoven; 2007.

[36] Smooke MD, Giovangigli V. Formulation of the premixed and nonpremixed test problems. In: Smooke MD, editor. Reduced kinetic mechanisms and asymptotic approximations for methane-air flames384. Berlin/Heidelberg: Springer; 1991. p. 1-28.

[37] Peters N. In: Peters N, Rogg B, editors. Reduced kinetic mechanisms for applications in combustion systems, lecture notes in physics15. Heidelberg: Springer-Verlag; 1993. p. 1-13. 